\title{
French take physics archives into the future
}

Declan Butler, Paris

France's national research agency, the Centre National de la Recherche Scientifique (CNRS), is to establish a French arm of the Los Alamos preprint archives of physics papers. The move is part of wider plans being discussed by the International Union of Pure and Applied Physics (IUPAP) to upgrade and internationalize the archives.

The French arm, the Centre pour la Communication Scientifique Directe, will be based in Lyons and will consist of a handful of full-time computer scientists and engineers. Physicist Franck Laloe, who will head the unit, says it will be much more than a mirror site, aiming to develop the archives and extend them to other disciplines.

An international steering committee will meet later this month to advise the centre; it includes Paul Ginsparg, the founder of the Los Alamos archives, and Martin Blume, editor in chief of the American Physical Society.

"It's marvellous that CNRS are forwardlooking enough to try to forge the first formal elements of an international collaboration, and also to move beyond the primary physics and math components of the existing

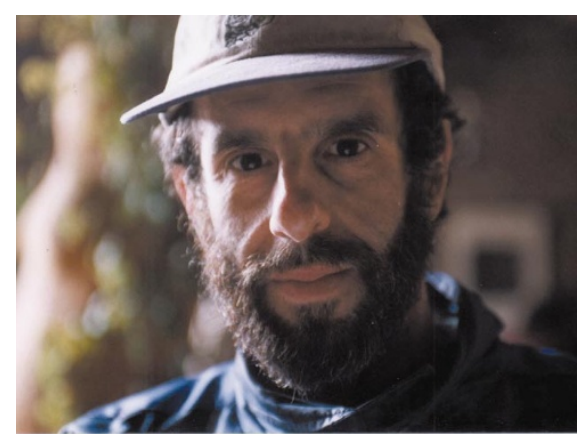

Ginsparg: backs international collaboration.

archives into other fields," says Ginsparg. "Ultimately, one could imagine every research institution and/or every funding agency joining in to help create the underlying data network."

Ginsparg has long argued that research institutions and their funding agencies should take greater control of the publication of raw research results.

"The costs of publishing on the Internet are a tiny fraction of what institutions pay in salaries and overheads for the research itself, and in this way they can ensure that the primary literature is made freely available," he says, adding that the cost of maintaining the
Los Alamos archives is as little as one dollar per article.

Blume says he is "delighted" about the CNRS decision. "At the meeting, I will encourage discussion about the establishment of an international consortium to support Paul Ginsparg in the operation and funding of his archive."

The IUPAP working group on communication in physics, which Blume chairs, last month recommended that the union should "play a role in assuring that there is international participation" in funding the archives, assuring availability and, if possible, aiding their operation "by mobilizing physics societies worldwide".

One drawback of the archives at present, says Blume, is that submissions can only be made through Los Alamos. To improve the situation, software needs to be developed that will allow submissions to be made at any one of the several mirror sites worldwide, he adds.

The American Physical Society (APS) initially viewed the archives as a competitor, but it is now actively collaborating. Since last year it has mirrored the archives, and uses them as an electronic submission procedure for APS journals.

\section{Anger as Princeton closes 'inspirational' museum}

\section{Rex Dalton}

Princeton University closed its Natural History Museum in Guyot Hall last month to provide space for a new environmental research unit. The move has angered university graduates and researchers worried that its historic collection may disappear into storage or be damaged when moved to a promised new facility.

Opened in 1909, the museum on the New Jersey campus drew large numbers of adults and children each year. It housed specimens from a century of palaeontological and geological discoveries by explorers from the university, including artefacts from a prehistoric Swiss village discovered in 1878, specimens of the moa - an extinct giant bird - and a virtually complete Allosaurus.

Princeton officials say they plan to house some specimens in a $\$ 65$ million extension, to be built in the next five years, which may combine biological, atmospheric and Earth sciences. But some current and former members of the geosciences department fear the collection could be broken up and distributed to other facilities, severing Princeton's ties to a golden era of discovery.

In the early 1980s, Princeton gave its vertebrate palaeontology research collection to Yale University, a move that prompted a similar swell of discontent. "The university is making a serious error in getting rid of this inspirational space," geology professor Lincoln Hollister wrote to Princeton president Harold Shapiro.

Hollister is among a group calling for a year's moratorium on dismantling the museum so funds can be raised to enhance it. Shapiro was unavailable for comment.

Meanwhile, the space is being converted into offices for the Environmental Institute, the recipient of major research grants from the National Science Foundation and British Petroleum, which is sponsoring research into carbon sequestration in old wells.

"I think it is deplorable that Princeton is closing the museum," says Lydia Fox, a Princeton graduate who is now chair of geosciences at the University of the Pacific in California. "A natural history museum can be a critical form of outreach to an increasingly science-illiterate citizenry."

More than 100 geoscience graduates have asked Princeton's president to reprieve the museum. Last month, a study showed the specimens were extremely valuable, but vulnerable to damage if moved.

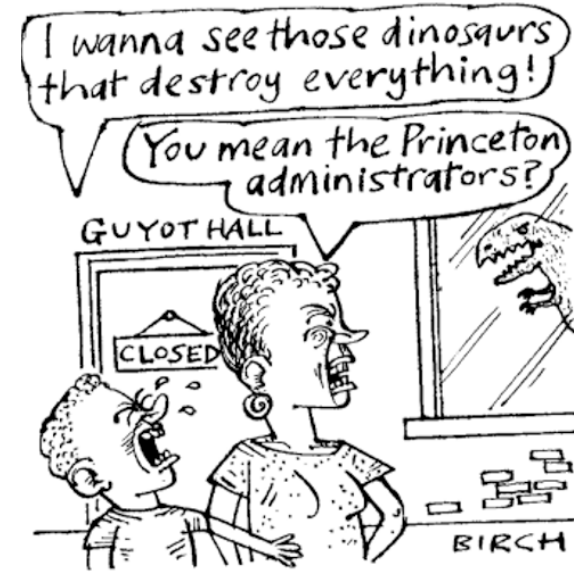

Oceanographer George Philander, Princeton's chairman of geosciences, is apologetic for the way that the university has handled the museum closure, saying he "completely underestimated the emotional attachment" to the facility.

But Philander insists that the planned new facility will be popular. Museums like the one in Guyot Hall "have been able to describe what the world was like," he says. "Now we are on the verge of being able to describe why the world is the way it is. We want a museum to reflect that." 